\title{
Patients' and Providers' Views on Causes and Consequences of Healthcare Fragmentation in the Ambulatory Setting: a Qualitative Study
}

\author{
Lisa M. Kern, MD, MPH', Monika M. Safford, MD', Masha J. Slavin, MD², Evguenia Makovkina, BA? , \\ Ahd Fudl, $B A^{7}$, J. Emilio Carrillo, $M D^{7}$, and Erika L. Abramson, MD, MS ${ }^{7}$ \\ ${ }^{1}$ Weill Cornell Medicine, New York, NY, USA; ${ }^{2}$ NewYork-Presbyterian Hospital, New York, NY, USA.
}

BACKGROUND: Patients with chronic conditions routinely see multiple outpatient providers, who may or may not communicate with each other. Gaps in information across providers caring for the same patient can lead to harm for patients. However, the exact causes and consequences of healthcare fragmentation are not understood well enough to design interventions to address them.

OBJECTIVE: We sought to elicit patients' and providers' views on the causes and consequences of healthcare fragmentation.

DESIGN AND PARTICIPANTS: We conducted a qualitative study with focus groups of patients and, separately, of providers (attending physicians and nurse practitioners) at an academic hospital-based primary care practice in New York City in June-August 2017. Patient participants were English-speaking adults with $\geq 2$ chronic conditions.

APPROACH: Each focus group lasted $1 \mathrm{~h}$ and asked the same two questions: "Why do you think some patients receive care from many different providers and others do not?" and "What do you think happens as a result of patients receiving care from many different providers?" Data collection continued until a point of data saturation was reached. Thematic analysis was used to identify themes and subthemes.

KEY RESULTS: We conducted 6 focus groups with a total of 46 participants (25 patients and 21 providers). Study participants identified 41 unique causes of fragmentation, which originate from 4 different levels of the healthcare system (patient, provider, healthcare organization, and healthcare environment); most causes were not related to medical need. Participants also identified 24 unique consequences of fragmentation, of which 3 were desirable and 21 were undesirable.

CONCLUSIONS: The results of this study offer a granular roadmap for how to decrease healthcare fragmentation. The large number and severity of negative consequences (including medical errors, misdiagnosis, increased cost, and provider burnout) underscore the urgent need for interventions to address this problem directly.

Electronic supplementary material The online version of this article (https://doi.org/10.1007/s11606-019-04859-1) contains supplementary material, which is available to authorized users.

Received June 5, 2018

Revised November 13, 2018

Accepted December 20, 2018

Published online February 19, 2019
KEY WORDS: ambulatory care; healthcare organization; healthcare delivery.

J Gen Intern Med 34(6):899-907

DOI: $10.1007 / \mathrm{s} 11606-019-04859-1$

๑) Society of General Internal Medicine 2019

\section{INTRODUCTION}

American healthcare is often described as "fragmented," with patients routinely receiving care from multiple ambulatory providers. ${ }^{1}$ For example, Medicare beneficiaries see a median of 7 providers ( 2 primary care providers and 5 specialists) in 4 practices each year. ${ }^{2}$ Because different patients see different combinations of specific providers, the typical primary care physician has 229 other physicians in 117 practices with whom to coordinate care - for their Medicare beneficiaries alone. ${ }^{3}$ Because providers caring for the same patient do not always communicate with each other, ${ }^{4}$ fragmented care can lead to medication errors ${ }^{5}$ and other types of harm, such as preventable hospital admissions. $^{6}$

However, the reasons for fragmented care are not well understood. ${ }^{7}$ It is not known, for example, whether these patterns of care are driven by patient preferences, physician referrals, health system factors, or a combination of these. Similarly, the extent to which fragmented care is medically necessary vs. modifiable is not clear. While some effects of fragmented care have been documented, the full scope of consequences has not been determined.

The need to understand fragmented care has increased with the growth of alternative payment models for provider reimbursement. ${ }^{8}$ Under those models, providers are newly responsible for all of a patient's care, not just the care they deliver themselves. ${ }^{9}$ Knowing why patients go elsewhere and what happens when they do are critical for population management. Thus, our objective was to elicit the views of patients and providers on the causes and consequences of fragmented ambulatory care.

\section{METHODS}

\section{Overview}

We conducted a qualitative study at an academic primary care practice in New York, NY in June-August 2017. We 
conducted 1-h focus groups of patients and, separately, of providers. The Institutional Review Board of Weill Cornell Medicine approved the protocol.

\section{Setting}

The study took place in an academic blended facultyresident practice in New York, NY, that serves as the primary care base for its affiliated hospital. The practice provides approximately 56,000 ambulatory visits annually, of which approximately half reflects direct patient care by faculty and half reflects direct patient care by residents supervised by faculty. Patients in this practice primarily reside in the five boroughs of New York City, with the majority coming from the boroughs of Manhattan, Queens, and Brooklyn. The payer mix is approximately $28 \%$ commercial, $45 \%$ Medicare, 26\% Medicaid, and 1\% self-pay.

\section{Inclusion Criteria and Recruitment}

We described the study to the practice's attending physicians and nurse practitioners (NPs) and invited them to participate. We excluded house staff, because fragmentation of care in that provider population may have distinct causes and should be studied separately. Of a total of 38 attendings and NPs, 24 attended an informational meeting about the study and, of those, 18 agreed to participate; in addition, 3 providers who had conflicts with the informational meeting later learned about the study and agreed to participate, for a total of 21 providers $(21 / 38=55 \%)$.

We conducted a systematic search in the electronic health record (EHR) to identify patients who met the following inclusion criteria: (1) were $\geq 18$ years old, (2) had an attending physician or NP at the practice as their primary care provider, (3) were seen at the practice in the previous 12 months, (4) spoke English, and (5) had $\geq 2$ chronic conditions (from a specific list of the 15 most common chronic conditions treated in primary care: asthma, atherosclerosis, cerebrovascular disease, chronic kidney disease, chronic obstructive pulmonary disease, coronary artery disease, depression, diabetes mellitus, gastrointestinal reflux, hyperlipidemia, hypertension, migraine, obesity, osteoarthritis, and osteoporosis ${ }^{10}$ ) (Fig. 1). We selected patients with $\geq 2$ chronic conditions, because these patients were more likely to have fragmented care than patients with $<2$ chronic conditions. ${ }^{2}$

We stratified the list by primary care provider and took a random sample of 50 patients per provider. We asked the providers to identify which of their patients should not be approached for the study (for any reason), and then we reached out by mail and phone to those patients who had not been excluded by their providers. Through phone calls, we confirmed an additional inclusion criterion: that patients had $\geq 2$ providers outside the practice (as a proxy for experience with healthcare fragmentation). Of the first 73 patients we reached, 8 were not eligible. Of the remaining 65 patients, 34 expressed willingness to participate (52\%). We also advertised with flyers in the practice's waiting rooms, attracting 7 patients. We enrolled consecutive patients who agreed to participate and were available on the dates of the planned focus groups.

Each patient and provider who participated was given lunch during the focus group. Patients also received a $\$ 25$ gift card and round-trip Metro-Card for transportation.

\section{Data Collection}

We chose to conduct focus groups rather than individual interviews, because we sought to encourage brainstorming among study participants; focus groups can be useful for "facilitating the expression of ideas and experiences that might be left underdeveloped in an interview." 1 -h focus groups in conference rooms of the practice for patients and, separately, providers. Each focus group was led by a female physician-investigator (LMK or MMS). Other members of the research team were also present (ELA, MJS, EM, AF, JEC).

Participants completed written consent forms and brief demographic questionnaires. Using a focus group guide refined by the research team, participants were told that the purpose of the discussion was to collect opinions on why some patients receive care from multiple doctors and what happens after they do. Participants were given basic statistics on how common it is for patients to see multiple doctors. They were told that seeing multiple doctors may be clinically appropriate but may also create challenges. Participants were told that there were no right or wrong answers.

We specifically asked each focus group to answer the same two questions: "Why do you think some patients receive care from many different doctors and others do not?" and "What do you think happens to patients when they receive care from many different doctors?" We probed for both positive and negative consequences. We encouraged brainstorming of as many answers as the group could generate.

Field notes were taken by members of the research team, and focus groups were audio-recorded and transcribed, removing any identifiers during transcription. To encourage reflexive thinking, members of the research team discussed their perspectives and immediate reactions after each focus group. ${ }^{12}$ Transcripts were reviewed by two members of the research team (LMK and ELA) as they were generated, and data collection continued until thematic saturation was reached.

\section{Data Analysis}

We hypothesized that the data would align with the "systems approach to healthcare delivery" conceptual framework. ${ }^{13}$ This framework describes a four-level 


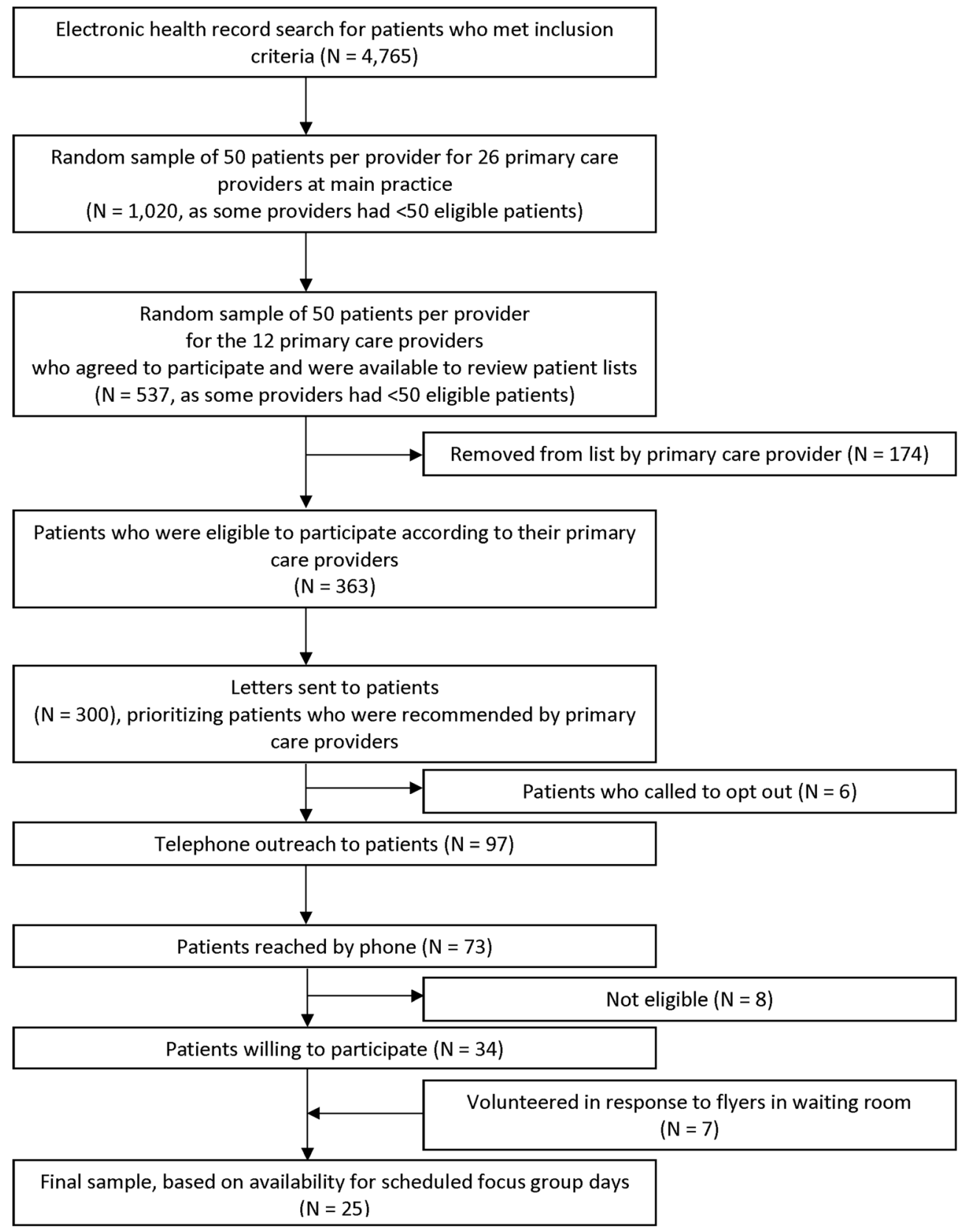

Fig. 1 Flow diagram describing patient recruitment.

model of healthcare: the patient is at the center, surrounded by the care team, which is surrounded by the organization, which is surrounded by the environment. ${ }^{13}$ This framework was originally designed to capture healthcare changing from a "cottage industry" (in which many parts of the healthcare system act independently) to a "system" (in which each part of the healthcare system recognizes its "dependence and influence" on other parts). ${ }^{13}$ This framework had not been previously applied to understanding the issue of fragmentation per se.

Using NViVO 11 software, at least two investigators (including LMK and ELA) coded each transcript together, reconciling discrepancies by discussion until consensus was reached. ${ }^{14}$ We used a thematic framework approach ${ }^{11}$ to identify themes that emerged, cognizant of but not restricted to the conceptual framework described above. The codes for patient and provider focus groups overlapped extensively, such that we created one set of themes and subthemes, representing the views of patients and providers collectively. We discussed emerging themes and subthemes with the whole research team, to ensure that coding was consistent with what they had heard. To promote transparency, we included quotations in both the results section and in appendices, to allow readers sufficient evidence for evaluating the themes and subthemes we articulated. ${ }^{11}$ 
Table 1 Characteristics of the Study Participants

\begin{tabular}{|c|c|}
\hline \multicolumn{2}{|l|}{ Characteristic } \\
\hline PATIENTS & $N=25$ \\
\hline Age, years, mean (sd) & $64.5(8.9)$ \\
\hline Gender, female, $N(\%)$ & $18(72)$ \\
\hline \multicolumn{2}{|l|}{ Race, $N(\%)$} \\
\hline White & $16(64)$ \\
\hline Black & $8(32)$ \\
\hline Asian & $0(0)$ \\
\hline Missing & $1(4)$ \\
\hline \multicolumn{2}{|l|}{ Ethnicity, $N(\%)$} \\
\hline Hispanic & $2(8)$ \\
\hline \multicolumn{2}{|l|}{ Education } \\
\hline 8th grade or less & $1(4)$ \\
\hline Some high school & $4(16)$ \\
\hline High school graduate & $6(24)$ \\
\hline College graduate & $5(20)$ \\
\hline More than college education & $8(32)$ \\
\hline Missing & $1(4)$ \\
\hline \multicolumn{2}{|l|}{ Health insurance* } \\
\hline Medicare & $18(72)$ \\
\hline Medicaid & $8(32)$ \\
\hline Private insurance & $6(24)$ \\
\hline Other insurance & $1(4)$ \\
\hline No insurance & $0(0)$ \\
\hline \multicolumn{2}{|l|}{ Chronic conditionst } \\
\hline \multicolumn{2}{|l|}{15 named conditions } \\
\hline Hypertension & $19(76)$ \\
\hline Hyperlipidemia & $14(56)$ \\
\hline Diabetes & $11(44)$ \\
\hline Gastrointestinal reflux & $9(36)$ \\
\hline Osteoarthritis & $9(36)$ \\
\hline Coronary artery disease & $6(24)$ \\
\hline Depression & $5(20)$ \\
\hline Obesity & $5(20)$ \\
\hline Asthma & $3(12)$ \\
\hline Chronic kidney disease & $3(12)$ \\
\hline Osteoporosis & $3(12)$ \\
\hline Cerebrovascular disease & $2(8)$ \\
\hline Chronic obstructive pulmonary disease & $2(8)$ \\
\hline Atherosclerosis & $1(4)$ \\
\hline Migraine headaches & $0(0)$ \\
\hline \multicolumn{2}{|l|}{ Otherț } \\
\hline Cancer & $4(16)$ \\
\hline Fibromyalgia & $1(4)$ \\
\hline Hemochromatosis & $1(4)$ \\
\hline Liver disease & $1(4)$ \\
\hline Multiple sclerosis & $1(4)$ \\
\hline Polycystic ovary syndrome & $1(4)$ \\
\hline Thyroid disease & $1(4)$ \\
\hline Valvular disease & $1(4)$ \\
\hline \multicolumn{2}{|l|}{ Self-reported health } \\
\hline Excellent & $3(12)$ \\
\hline Very good & $8(32)$ \\
\hline Good & $10(40)$ \\
\hline Fair & $3(12)$ \\
\hline Poor & $1(4)$ \\
\hline Outpatient visits in past year, mean (sd) & $12.0(15.3)$ \\
\hline Outpatient providers in past year, mean (sd) & $4.1(2.5)$ \\
\hline PROVIDERS & $N=21$ \\
\hline \multicolumn{2}{|l|}{ Type of provider, $N(\%)$} \\
\hline Attending physician & $17(81)$ \\
\hline Nurse practitioner & $4(19)$ \\
\hline Years since graduation from medical or nursing school, mean (sd) & $22.0(12.3)$ \\
\hline Years at practice, mean (sd) & $13.3(11.9)$ \\
\hline Gender, female, $N(\%)$ & $12(57)$ \\
\hline \multicolumn{2}{|l|}{ Race, $N(\%)$} \\
\hline White & $14(66)$ \\
\hline Black & $1(5)$ \\
\hline Asian & $6(29)$ \\
\hline \multicolumn{2}{|l|}{ Ethnicity, $N(\%)$} \\
\hline Hispanic & $2(10)$ \\
\hline Half-days per week providing ambulatory care, mean (sd) & $3.2(2.2)$ \\
\hline Half-days per week supervising residents, mean (sd) & $1.7(1.2)$ \\
\hline
\end{tabular}

\section{RESULTS}

\section{Sample}

We conducted 3 focus groups of patients ( $7-10$ patients per group for a total of 25 patients) and 3 focus groups of providers (6-9 providers per group for a total of 21 providers).

The average patient was 64.5 years old (Table 1). Nearly three-fourths of the patients were female (72\%). Approximately two-thirds of the patients were white and one-third were black. Nearly $10 \%$ were Hispanic. Approximately half of participants (52\%) had a college degree. All participants had health insurance, with Medicare (72\%) being the most common insurer. Patients had a variety of chronic conditions, with the most frequent being hypertension (76\%), hyperlipidemia (56\%), and diabetes $(44 \%)$. Fewer than half of participants rated their health as excellent $(12 \%)$ or very good $(32 \%)$. The average participant reported having had 12 ambulatory visits in the past year with 4 unique providers.

Most providers (81\%) were attending physicians; $19 \%$ were nurse practitioners. The average provider had graduated from medical or nursing school 22 years ago and had worked at this practice for 13 years. Approximately half of the providers (57\%) were female. The racial distribution of providers was $66 \%$ white, $29 \%$ Asian, and 5\% black. Of the total, $10 \%$ were Hispanic. The average provider spent 3.2 half-days per week seeing his or her own patients and 1.7 half-days per week supervising residents in ambulatory care.

\section{Causes of Fragmentation}

Participants identified causes of fragmentation at each of the 4 levels of the Systems Approach framework: the patient, the provider (or care team), the organization, and the environment (themes). The participants further articulated specific causes of fragmentation within each level (subthemes): 15 causes at the patient level, 7 at the provider level, 8 at the organization level, and 11 at the environment level, for a total of 41 unique causes of fragmentation (Table 2). The themes and selected subthemes are described in more detail below (see Online Appendix 1 for quotations for each of the subthemes). Participants are numbered in the quotes below only as needed to distinguish voices in a common conversation; patient 1 in one quote may not be the same individual as patient 1 in another quote.

Patient-Level Causes of Healthcare Fragmentation. We found that patients may seek care from multiple providers due to individual medical needs or personal preferences. For example, participants reported that patients may need consultations from providers in different specialties:

Patient: "Well, because of different things. I have a urinary doctor. I have a pulmonary doctor. I got a heart specialist; I had a stroke. I must got about maybe ten doctors. For different things.” 
Table 2 Full List of 41 Unique Causes of Healthcare Fragmentation (Subthemes), as Reported by Patients and Providers, Stratified by the Level of the Healthcare System from Which the Cause Originates (Theme)

\begin{tabular}{|c|c|}
\hline Theme & Subtheme \\
\hline Patient-level causes & $\begin{array}{l}\text { 1. Dissatisfaction with a doctor's bedside manner } \\
\text { 2. Distrust of a doctor's clinical assessment } \\
\text { 3. Doctor shopping until one gets a certain clinical answer } \\
\text { 4. Lack of knowledge of potential benefits of having a primary care provider to coordinate and consolidate care } \\
\text { 5. Lack of knowledge of primary care scope of practice } \\
\text { 6. Low literacy and low educational attainment as risk factors for difficulty navigating healthcare } \\
\text { 7. Medical need for consultation (different specialty), from patient's perspective } \\
\text { 8. Medically appropriate second opinion (same specialty), from patient's perspective } \\
\text { 9. Mental illness (e.g. personality disorders) } \\
\text { 10. Preference for attention to customer experience } \\
\text { 11. Preference for being seen by a specialist (vs. generalist) } \\
\text { 12. Preference for being seen quickly } \\
\text { 13. Preference for convenience due to geography } \\
\text { 14. Preference for receiving at least some care from an academic medical center } \\
\text { 15. Uncertainty about whom to call or see }\end{array}$ \\
\hline Provider-level causes & $\begin{array}{l}\text { 16. Fear of patient dissatisfaction if a patient's request for referral is denied } \\
\text { 17. Lack of time for educating patients on why some referrals may not be necessary } \\
\text { 18. Lack of time for handling all of a patient's medical issues and choosing to refer instead of scheduling another } \\
\text { appointment with the primary care physician } \\
\text { 19. Medical need for consultation (different specialty), from provider's perspective } \\
\text { 20. Not explaining to patients the need to return to primary care } \\
\text { 21. Specialists refer to other specialists, bypassing primary care providers } \\
\text { 22. Sub-specialization (within specialties, such as within orthopedics) }\end{array}$ \\
\hline $\begin{array}{l}\text { Organization-level } \\
\text { causes }\end{array}$ & $\begin{array}{l}\text { 23. Complexity of the system } \\
\text { 24. Coverage structure (i.e., many doctors cover for each other and are not familiar with others' patients) } \\
\text { 25. Discharge process from emergency department includes referrals to other providers } \\
\text { 26. Discharge process from hospital includes referrals to other providers } \\
\text { 27. Expectations for high volume of patients leads to full schedules and limited availability when the patient calls } \\
\text { 28. Hospitalists call consultants before calling primary care physician } \\
\text { 29. Phones are busy and patients cannot get through so go elsewhere } \\
\text { 30. Practices decide which insurance plans are accepted and those decisions change over time (so some patients can no longer } \\
\text { be seen as easily) }\end{array}$ \\
\hline $\begin{array}{l}\text { Environment-level } \\
\text { causes }\end{array}$ & $\begin{array}{l}\text { 31. Health insurance is often tied to employment and patients may change jobs } \\
\text { 32. Health systems advertise areas of expertise } \\
\text { 33. Financial incentives } \\
\text { 34. Lack of transparency around costs } \\
\text { 35. Large supply of providers in a small geographic area makes it easy to see different providers } \\
\text { 36. Patients' employers change which insurance products they offer } \\
\text { 37. Payer rules encourage extra visits to authorize referrals } \\
\text { 38. Payers allow self-referral to subspecialists } \\
\text { 39. Payers specify which providers are "in network" } \\
\text { 40. Urgent care clinics are available and easy to use for acute problems } \\
\text { 41. Urgent care clinics are expanding into providing primary care (in addition to urgent care) }\end{array}$ \\
\hline
\end{tabular}

Causes are listed in alphabetical order within theme

Participants also said that patients may need a second opinion from a provider in the same specialty as a provider he or she already sees:

Patient: "I saw the orthopedic that she had recommended to me. He right away wanted to operate and put screws in me. I called Dr. [Name], who was my bone doctor at the time, who retired...He said 'Absolutely not. I'm gonna get you in for a second opinion.' I went in for that second opinion....He did not operate on me. I had no surgery. I had to take it easy....and I'm perfectly fine."

Participants acknowledged that patients' convenience due to geography was another factor:

Patient: "But one of the problems that I've had recently is, because of geography, I live in New Jersey, one of my specialists is in New Jersey. Different system. So that has been a challenge because the communication does not exist between [my hospital in New York] and [my town] in New Jersey. So that's been a challenge, but that's basically why I would go to a few different doctors."

Participants also highlighted patient preferences related to timeliness:

Patient: "I prefer going where I can get an appointment quickly. That's really what's important to me, and I notice a lot of doctors, they're really packed and you have to wait almost, like three months to get an appointment, if you're new, especially."

Provider-Level Causes of Healthcare Fragmentation. We found that providers' behavior contributed to healthcare fragmentation. For example, participants described providers' willingness to refer due to lack of time: 
Provider 1: "...if you had all the time in the world, you could educate the patient on when...a neurologist would be necessary for the management of a headache, but when you're already 12 minutes past -"

Provider 2: “- sometimes it's easier to refer."

Patient 1: "They don't have time - "

Patient 2: "And that's why we have to see multiple doctors."

Participants also explained how provider sub-specialization caused fragmentation:

Patient 1: "Everything is a specialty."

Patient 2: "Yeah. Everything is a specialty and a subspecialty."

Patient 1: "So we don't have a choice."

Patient 3: "That's right."

Patient 4: "[The doctors would say] 'I only do knees.'

'I only do ankles.' That type of thing."

In addition, participants said that specialists may refer patients directly to other specialists, bypassing primary care providers and increasing fragmentation.

Provider: "Sometimes it's also perpetuated by subspecialists. They would say, 'Oh, if you go see the cardiologist for high blood pressure, go see an endocrinologist for diabetes, go see a pulmonologist because you develop a cough."”

Participants explained that providers sometimes give referrals that may not be medically necessary, out of fear of patient dissatisfaction:

Provider: “....in the community model if you're a private physician and a patient is demanding a referral and you refuse you're gonna lose that patient."

Organization-Level Causes of Healthcare Fragmentation. Organization-level causes of fragmentation included policies and patterns of care directed by the medical practice and/or hospital. For example, participants explained that practices' decisions regarding which insurance plans to accept affected fragmentation:

Patient 1: "Well, Medicare. I mean, so I'm on Medicare, so I go to a Medicare doctor, and I understand every two years they have the choice of opting in or opting out. So I could go to a doctor who I really like, and two years later - "

Patient 2: "And then they drop you."
Patient 3: "That's a problem."

Provider: "...organizations change insurances basically from year to year, contract to contract, which leaves patients at the short end of the stick."

Participants noted that discharge processes from the hospital influenced how many providers patients saw:

Provider: "I also find that many of my patients who are hospitalized, their discharge summaries...[will] now have three new specialty outpatient appointments that were already set up rather than [telling the patient to] go back to your primary doctor to talk about whether or not you might need a pulmonologist or an endocrinologist or whether your primary doctor will be comfortable managing these problems if they settle down after your recent admission. That sort of happens automatically."

Environment-Level Causes of Healthcare Fragmentation. Other stakeholders in the healthcare environment (outside of the healthcare system) can also cause fragmentation. For example, payers' decisions regarding which providers are "in network" affect fragmentation:

Provider: "It's like, well [if I'm the patient] I have to figure out what's available to me on the dim sum menu of providers, and I'll make my list and I'll have this list ready to go...I know that the patient [has] already done their legwork to figure it out, not because someone recommended that doctor but mainly because it was a payer constraint. They figured out who could actually see them."

The rise of urgent care clinics was cited as another factor:

Patient 1: "People can run in -"

Patient 2: "I have to tell you, they're wonderful."

Patient 1: "I haven't gone myself, but people run into those places, and maybe that's why they end up with more than one doctor."

Provider 1: "It's super convenient. It's so easy for a patient to walk into [name of urgent care clinic] that's literally across the street from where they live or next to their office and open late. It's so smooth and customerservice oriented the way they run those practices that for a relatively minor thing it's very appealing, and we can't offer that kind of service."

Provider 2: "They also do what the patient wants."

Provider 3: "They get a Z-pack."

Provider 2: "Every patient gets a Z-pack." 
Employers were described as another environmental factor:

Provider: "So outside of the Medicare population, insurance, I think is less stable than it used to be, and a lot of people are changing insurances more rapidly. Even without changing a job, sometimes the company will choose a different one.....and that leads to a whole new set of doctors that they have to see. So I think that's another reason why there may be more fragmentation."

\section{Consequences of Healthcare Fragmentation}

Participants articulated 24 different consequences of healthcare fragmentation, of which 3 were positive (desirable) and 21 were negative (undesirable) (Table 3). Quotations illustrating selected consequences appear below (see Online Appendix 2 for quotations for each of the consequences).

Participants described positive consequences of healthcare fragmentation, such as appropriate medical consultation:

Provider: "Sure, primary care doctors don't know everything and getting to see a specialist can more easily and rapidly make the diagnosis that we overlook from time to time."

Higher patient satisfaction was described as another desirable outcome:

Patient: "So I think we all agree seeing multiple doctors, as long as they communicate with one another, even if they're not in the same system, but it's a matter of you carry your notes or some doctors call each other. I think it's a good thing."

Provider 1: "Sometimes patients are happy."

Provider 2: "It improves their satisfaction."

Participants described numerous negative consequences of healthcare fragmentation, such as gaps in clinical information across providers caring for the same patient:

Patient: "I think the consequences of having many different doctors is that you run the risk of having something go wrong, because they're not informed..."

Participants linked those gaps in clinical information to other negative consequences, such as having more medications prescribed inappropriately:
Table 3 Consequences of Healthcare Fragmentation, as Reported by Patients and Providers

\begin{tabular}{|c|c|}
\hline Theme & Subtheme \\
\hline $\begin{array}{l}\text { Positive (desirable) con- } \\
\text { sequences }\end{array}$ & $\begin{array}{l}\text { 1. Appropriate medical consultation } \\
\text { (different specialty) } \\
\text { 2. Higher patient satisfaction } \\
\text { 3. Strengthened relationship between } \\
\text { patient and primary care physician (when } \\
\text { consulting physician agrees with primary } \\
\text { care physician's assessment) }\end{array}$ \\
\hline $\begin{array}{l}\text { Negative (undesirable) } \\
\text { consequences }\end{array}$ & $\begin{array}{l}\text { 4. Conflicting advice } \\
\text { 5. Disruption to patient-primary care pro- } \\
\text { vider relationship } \\
\text { 6. Drug-drug interactions } \\
\text { 7. Failure to detect clinical patterns } \\
\text { 8. Gaps in clinical information } \\
\text { 9. Higher cost for healthcare overall } \\
\text { 10. Higher out-of-pocket costs for patients } \\
\text { 11. Inadvertent prescribing of duplicate } \\
\text { medications } \\
\text { 12. Inappropriate referrals } \\
\text { 13. Increased risk of being sued for } \\
\text { malpractice due to gaps in information } \\
\text { 14. Loss of revenue from time spent } \\
\text { addressing fragmentation } \\
\text { 15. Medication errors } \\
\text { 16. Misdiagnosis, or failure to identify the } \\
\text { correct diagnosis } \\
\text { 17. More medications prescribed } \\
\text { inappropriately } \\
\text { 18. More patient time used } \\
\text { 19. More provider time used } \\
\text { 20. More referrals made unnecessarily } \\
\text { 21. More tests ordered and completed } \\
\text { unnecessarily } \\
\text { 22. More unnecessary visits } \\
\text { 23. Poor patient outcomes } \\
\text { 24. Provider burnout }\end{array}$ \\
\hline
\end{tabular}

Consequences are listed in alphabetical order within theme

Provider: "[Patients] think that the doctor who's seeing them at another institution knows magically everything that we've done to them and thought, and then they go there - they get iatrogenesis imperfecta. They get everything done to them again. They get a whole new set of meds. 'Oh, you shouldn't be on those meds.' So patients suffer from that."

Participants further linked more medications being prescribed to more medication errors:

Provider: "Patients don't always bring in everything, and there's very often harm or potential harm that we see when physicians don't understand all the medications that they're taking. That's an obvious one.”

Participants reported that fragmentation can lead to unnecessary testing:

Patient: "I mean, one of the problems I encountered...[I] passed out,...went to a cardiologist. Okay, that was fine...so she sends me to an electrophysiologist. I then 
had a battery of so many unnecessary tests. I can't even tell you. So it was like, 'What are you doing?'... it wound up getting to the point of so much unnecessary medical testing, that I thought, 'This is ridiculous. I should've stopped at the primary care.'"

Participants also reported that fragmentation can result in misdiagnosis:

Provider: "...I also saw a marathon winner the other day who had dyspnea on exertion for many years and saw a pulmonologist and a cardiologist and probably some other specialist, and she had iron deficiency anemia, and I told her that, and she was like, 'But why didn't anyone else tell me that, because my hemoglobin was nine two years ago?' I said, 'Because your cardiologist's perspective is your heart, and so if they don't find anything with your heart they're gonna tell you you're okay and they're right'...so she had this 'a-ha' moment like, 'Oh my God, I wasted two years and 12 specialists, and the answer is my periods?'"

Participants asserted that fragmentation leads to higher healthcare costs:

Provider 1: "Well, I think if you look at it more globally, that's also why healthcare costs are so high. Patients don't see the actual cost of their visit. It's paid for by the insurance, so they go see different doctors. Who cares? \$5.00 co-pay, no big deal, but it's unnecessary." Provider 2: "It's not just the direct cost, of course. It's the follow-up cost from the [unnecessary testing and the] false positives."

In addition, participants made a direct connection between fragmentation and provider burnout:

Provider 1: "Fragmentation I think also negatively impacts on the providers, which makes it a challenge...we're doctors and nurse practitioners, we've been trained to take care of patients, and our lives are spent with 'Please enter these eight referrals for this patient and please hunt down these records and please coordinate this care, speak to this doctor at another institution' that we end up feeling very clerical, and it negatively impacts psychologically our ability to take care of patients."

Provider 2: “...I think there's a job satisfaction and a personal fulfillment burnout issue especially for the patient who sees...a specialist for every single little problem and then you're kind of like, 'Well, what am I for?",

Provider 3: "Glorified secretary."
Patient: "It's 15 minutes, and they're rushing everywhere. They're overwhelmed too. We're overwhelmed, and they're overwhelmed."

\section{DISCUSSION}

This qualitative study of patients and providers revealed 41 causes of healthcare fragmentation, arising from different levels of the healthcare system, and 24 consequences of healthcare fragmentation, of which 3 are desirable and 21 are undesirable. To our knowledge, this is the first study to systematically elicit a comprehensive list of the causes and consequences of healthcare fragmentation.

Previous studies have estimated (through expert opinion) that "when patients fall through the slats in fragmented care," it costs American society $\$ 25$ billion to $\$ 45$ billion annually. ${ }^{15}$ However, exactly why fragmented care occurs had not been explained. Other experts have called for this type of study, arguing that the reasons why patients use multiple providers are "poorly understood," have been "largely ignored in the payment reform debate," and that understanding those reasons can serve as "a linchpin for increasing the value of care."16 Still, others have noted that, although there is relatively broad consensus that fragmentation is a source of inefficiency, there is "surprisingly little" evidence of its effects. ${ }^{7}$ Those authors have argued that it had not yet been proven that fragmentation is not "simply a reflection of the fact that sicker patients see more providers."7

The results of this study demonstrate that fragmentation is not just a function of sicker patients seeing more providers. Rather, patients and providers agree that the causes of fragmentation are numerous, multi-factorial, and go beyond medical need. There have been previous policy initiatives designed to incentivize "care coordination," but these initiatives have had mixed results. ${ }^{17}$ They have largely focused on addressing patients' medical needs and on improving communication among the patient and members of the care team. While important, these areas of focus may underestimate the full scope of challenges for care coordination, as articulated by our study participants.

This study has several limitations. Although our study participants identified $>40$ causes and $>20$ consequences of healthcare fragmentation, it is possible that others may identify additional causes and consequences. For example, we did not include specialist physicians, health system administrators, or payers, who may know of causes and consequences that our study participants did not mention. In addition, because this is a qualitative study, we cannot determine the relative frequency or relative importance of the causes and consequences we identified. This study took place at one hospital-based practice; its results could be used to inform the design of a survey, which could test the generalizability of these findings.

The implication of our study is that addressing the causes of fragmentation would require interventions at the patient, 
provider, organization, and environment levels. No single intervention would likely be able to address all of these levels simultaneously, so a set of coordinated interventions would be needed. Accountable care organizations and other entities with value-based payments have incentives to avoid "leakage" of ambulatory visits to providers outside their organizations. ${ }^{18,19}$ However, the same organizations have lacked effective strategies for accomplishing this. ${ }^{18}$

The results of this study offer a granular roadmap for how to decrease healthcare fragmentation. The large number and severity of negative consequences of fragmentation (including medical errors, misdiagnosis, increased cost, and provider burnout) underscore the urgent need for interventions to address this problem.

Acknowledgements: The authors would like to thank Judy Tung, $M D$ and Fred Pelzman, MD for their support of this project. The authors would also like to thank the patients and providers who participated in this study and contributed their experiences and insights.

Corresponding Author: Lisa M. Kern, MD, MPH; Weill Cornell Medicine, New York, NY, USA (e-mail: lmk2003@med.cornell.edu).

Funders This work was funded by the Weill Cornell Institute for Primary Care Innovation.

\section{Compliance with Ethical Standards:}

The Institutional Review Board of Weill Cornell Medicine approved the protocol.

Conflict of Interest: The authors declare that they do not have a conflict of interest.

Publisher's Note: Springer Nature remains neutral with regard to jurisdictional claims in published maps and institutional affiliations.

\section{REFERENCES}

1. Elhauge E, ed. The fragmentation of U.S. health care: Oxford University Press; 2010.

2. Pham HH, Schrag D, O'Malley AS, Wu B, Bach PB. Care patterns in Medicare and their implications for pay for performance. N Engl $J$ Med 2007;356:1130-9.

3. Pham HH. O'Malley AS, Bach PB, Saiontz-Martinez C. Schrag D. Primary care physicians' links to other physicians through Medicare patients: the scope of care coordination. Ann Intern Med 2009;150:23642

4. O'Malley AS, Reschovsky JD. Referral and consultation communication between primary care and specialist physicians: finding common ground. Arch Intern Med 2011;171:56-65.

5. Anderson G, for the Robert Wood Johnson Foundation. Chronic care: Making the case for ongoing care, 2010. (Accessed December 11, 2018, at https://www.rwjf.org/en/library/research/2010/01/chronic-care. html.)

6. Nyweide DJ, Anthony DL, Bynum JP, et al. Continuity of care and the risk of preventable hospitalization in older adults. JAMA Intern Med 2013;173: 1879-85.

7. Frandsen BR, Joynt KE, Rebitzer JB, Jha AK. Care fragmentation, quality, and costs among chronically ill patients. Am J Manag Care 2015;21:355-62.
8. Burwell SM. Setting value-based payment goals-HHS efforts to improve U.S. health care. N Engl J Med 2015;372:897-9.

9. Berwick DM. Making good on ACOs' promise-the final rule for the Medicare shared savings program. N Engl J Med 2011;365:1753-6.

10. Ornstein SM, Nietert PJ, Jenkins RG, Litvin CB. The prevalence of chronic diseases and multimorbidity in primary care practice: a PPRNet report. J Am Board Fam Med 2013;26:518-24.

11. Pope C, Mays N, eds. Qualitative Research in Health Care, 2nd ed. London: BMJ Books; 2000.

12. Robert Wood Johnson Foundation Qualitative Research Guidelines Project: Reflexivity. 2008. (Accessed December 11, 2018, at http:// www.qualres.org/HomeRefl-3703.html.)

13. Reid PP, Compton WD, Grossman JH, Fanjiang G, eds. A framework for a systems approach to health care delivery. Building a better delivery system: A new engineering/health care partnership. Washington, DC: National Academies Press; 2005.

14. GSR International. NVivo software for qualitative data analysis, 2016. (Accessed December 11, 2018, at http://www.qsrinternational.com/ product.)

15. Berwick DM, Hackbarth AD. Eliminating waste in US health care. JAMA 2012;307:1513-6.

16. Song Z, Sequist TD, Barnett ML. Patient referrals: a linchpin for increasing the value of care. JAMA 2014;312:597-8.

17. Peikes D, Chen A, Schore J, Brown R. Effects of care coordination on hospitalization, quality of care, and health care expenditures among Medicare beneficiaries: 15 randomized trials. JAMA 2009;301:603-18.

18. Barnett ML, McWilliams JM. Changes in specialty care use and leakage in Medicare accountable care organizations. Am J Manag Care 2018;24:e141-9.

19. McWilliams JM, Chernew ME, Dalton JB, Landon BE. Outpatient care patterns and organizational accountability in Medicare. JAMA Intern Med 2014;174:938-45. 